\title{
Turning Social Capital into Real Capital
}

\section{Joseph A. Rosendale, Indiana University of Pennsylvania, USA}

\begin{abstract}
This interpretive research study analyzes organizations' ability to increase capital and financial gains through the integration of social communications among workers and other stakeholders. Using Vygotsky's social capital theory as a framework, it is recommended that businesses focus on building more systemic and systematic interpersonal, online, and social relationships as a valid means for competitive advantage and increased profitability.
\end{abstract}

Keywords: Social capital, business capital, social learning theory, online interaction 


\section{Introduction}

In economic and business terms, capital is oftentimes referred to, in a Marxian sense, as financial assets including money, resources, and commodities. However, modern organizational structures may allow for capital to now include social connections between individuals and groups.Progressive thinkers, such as Brenden McCooney (2008), use the term capital in a linear and more holistic sense; describing it as a relational flow between initial money spent and the resulting ends. The capital gain would be, therefore, the monetary increase resultant of the preliminary expenditure. It is in this sense that social capital may be gained through a business's investment in online community networks which could produce tangible fiscal gains for the organization.

This report will focus on the organizational expansion efforts involving social capital, which, in turn, may lead to increases in both human capital and overall financial capital. The notion of value expansion will be the underlying notion of this report; operationally defined by this researcher as: resource allocation toward a specific area that results in more overall value (output) than what was initially spent (input), thus, increasing the overall capital for the organization. Theoretical areas such as connectivism, social exchange theory, and human capital theory will be discussed, along with a heuristic analysis of current research in the field.

Thesis:Organizations need to allocate resources toward internal and external online social networks that aim to promote bonding and bridging relationships with internal constituencies as well as external stakeholders. In doing so, the increase in individual and groups' social capital and work efficacy should result in more effective business practices and a profitable return on their social networking investment.

\section{Synthetic Discussion of Current Literature}

A review of the current research in the area of online social media with a specific focus on community-building has resulted in three emergent themes that will be discussed in this report. They are: theory-based paradigms, effective online communities through culture, and gains in social capital due to relationships built or expanded on the Internet. 
Applicable theory - Lev Vygotsky's (1978) psychological approach to learning, as it relates to social capital, can be used to explain that an individual's personal capital (meaning their intelligence, talent, and abilities)can be exponentially increased from their network of acquaintances and personal relationships. Studies into social capital theory further expand on this notion. Researchers such as Kavanaugh et. al. (2005) show that the collective nature of online social media networks increase users' perceptions of “...collective efficacy, membership, belonging, activism, and...social aspects of community life." Moreover, the researchers believe that these online capabilities will directly transfer to individuals' face-to-face interactions (Kavanagugh et. al., 2005).Furthermore, the theory of connectivism can be used as a construct for interpreting the value of online social networks with regard to business opportunities. The emergent phenomena of connected personal learning networks in modern training practice specifically MOOCs - are able to link each members' current knowledge to novel materials and resources in order to create new meaning within the group. This way of looking at how knowledge transfers between participants, known as connectivism, states that new ways of learning in technology-supported online networks could result in greater retention and application of learned materials (Siemens, 2005).

Community-based, online networks may offer the ability for businesses to provide additional training and communication outlets to their workers, while at the same time countering the increasing budgetary restraints faced by many organizations. Philosopher and economist Adam Smith held the concept that investments in human capital, through training, could be analogous to increased productivity and profitability for labor industries and national economies (Smith, 2009). In turn, through the lens of human capital theory, the potential value of Interned-based networking could be realized when considering the business and communicative gains of hundreds or thousands of participants who otherwise would not have access to each other.

Effective online communities and culture -"Community is about human relationships; a group of people becomes a community when its members have some common, enduring connection" (Levinson, 2013, p. 13). With many businesses now having global stakeholder groups, theirformation of online social media networks should pay close attention to both the 
organization's overall community culture, as well as being sensitive to the predominant culture associated with the individual users of the site. Perhaps the most important aspect of implementing community-based social media sites in an organization would be audience considerations. From both educational and teaching-specific standpoints, online content designers "must determine whether teaching or training in technical communication needs to be modified to address the increasingly international nature of online interactions (Amant, 2011, p. 4). Hunsinger (2011) explains the need for, and challenges of, "localization" efforts when creating online content. He suggests that, "understanding the ways...online audiences construct a more general sense of locality... [including] political structures, legal frameworks, historical contexts, economic concerns, or scope of community" is the best way to localize online content (Hunsinger, 2011, p. 14). Additionally, Lanier (2011) offers a practical suggestion for localizing online content to users' preferences. His potential solution is, "to make the user, rather than the technical communicator, the localization expert (Lanier, 2011, p. 44). A built-in characteristic of new media is that, "every consumer is a producer" (Levinson, 2013). Therefore, the ability to give online design control to the actual individuals or employees may allow for better customization for end-users regarding technical communication tools, appropriating cultural indicators, the overall interface, and online specification options.

Social capital gains - Subscribers to social capital theory contend that there are collective benefits afforded to people who cooperate with each other, and, therefore, the group-effort is greater than the sum of its individual contributors. Two distinct areas, bonding and bridging, are used to explain interactional gains when using online community networks. First, bonding relationships are those formed within existing groups, whereas social bridging refers to the formation and strengthening of relationships between or across groups (Kavanaugh et. al., 2005). The application of increased bonding and bridging relationships to organizations would likely mean that individuals would have greater abilities for collaboration and teamwork within bonded groups and increased access to key peer-groups or opinion leaders due to bridged relationships online. Furthermore, in educational studies, empirical tests show that interactions among members on social networking sites, such as Facebook, result in statistically-significant increases in social capital indicators including "life satisfaction, social trust, civic participation, and 
political engagement (Valenzuela, Park, \& Kee, 2008).Objectively, though, it should be noted that other research has shown evidence that, depending on the users' familiarity and privacy concerns within online networking sites, there may be differences regarding levels of participation and, therefore, overall social networking gains realized (Dwyer, Hiltz, \& Passerini, 2007).

Lastly, positive implications can be clearly evidenced due to individuals' and groups' interactions on social media networks. However, additional measurement tools, such as those tested by Williams (2006) should be applied in order to statistically gauge the net increase of individuals' gains or losses of social capital after interactions and involvement in online community sites.

\section{Conclusion}

In the quest for ever-increasing profit margins, businesses should consider an updated model to traditional means of capital production. Typically, in capitalist economies, organizations spend money to purchase commodities and labor in order to produce goods or services to be sold for a profit. Through a synthetic review of applicable literature in the field of social capital, this researcher contends that money and resources that target the implementation or expansion of businesses' online community networks can be just as valuable to the bottom-line, if not moreso, than traditional means of production. Future research should focus on statistical cost/benefit analysis with special attention paid to organizations that invest money in community-building online networks and their overall net-profit margins. From the available research, it seems prudent to believe that organizational value-expansion and a positive return on investment would be likely outcomes. 


\section{References}

Amant, K. S., \& Sapienza, F. (2011).Culture, Communication \& Cyberspace: Rethinking Technical Communication for International Online Environments. Baywood Publishing Company, Incorporated.

Dwyer, C., Hiltz, S., \& Passerini, K. (2007). Trust and privacy concern within social networking sites: A comparison of Facebook and MySpace. AMCIS 2007 Proceedings, 339.

Hunsinger, R. P. (2011). Using global contexts to localize online content for international audiences.In: Culture, communication and cyberspace:Rethinking technical communication for international online environments, 13-37.

Kavanaugh, A., Carroll, J. M., Rosson, M. B., Zin, T. T., \& Reese, D. D. (2005). Community networks: Where offline communities meet online. Journal of Computer-Mediated Communication, 10(4).

Lanier, C. R. (2011). Making the user the localization expert: Employing user customization strategies in globalizing online content. In: Culture, communication and cyberspace: Rethinking technical communication for international online environments, 13-37.

Levinson, P. (2013). New new media ( $2^{\text {nd }}$ ed.). Boston, MA: Pearson.

McCooney, B. (2008). What is capital? Retrieved 26 October 2014, from: https://www.youtube.com/watch?v=HDvnSgJF4SE

Siemens, G. (2005). Connectivism: A learning theory for a digital age. International Journal of Instructional Technology and Distance Learning, 2(1).

Smith, A. (2009). The wealth of nations. Blacksburg, VA: Thrifty Books.

Valenzuela, S., Park, N., \& Kee, K. F. (2008, April).Lessons from Facebook: The effect of social network sites on college students' social capital. In 9th International Symposium on Online Journalism, Austin, TX.

Vygotsky, L.S. (1978). Mind in society. Cambridge, MA: Harvard University Press.

Williams, D. (2006). On and off the'Net: Scales for social capital in an online era. Journal of Computer-Mediated Communication, 11(2), 593-628. 